\title{
Best Paper Award
}

The following paper was selected by the Awards Subcommittee of the International Symposium on Superalloys as a co-winner of the Best Paper Award for the Ninth Symposium. The selection was based on the following criteria: originality, technical content, pertinence to the superalloy and gas turbine industries and clarity and style.

Predicting Grain Size Evolution of Udimet Alloy 718 during the "Cogging" Process through Use of Numerical Analysis

B.F. Antolovich and M.D. Evans 


\title{
Predicting Grain Size Evolution of UDIMET ${ }^{\circledR}$ alloy 718 During the "Cogging" Process Through the Use of Numerical Analysis
}

\author{
Bruce Antolovich* Mike Evans** \\ Special Metals Corporation,4317 Middle Setlement Rd, New Hartford, NY* \\ Electralloy, 175 Main St., Oil City, PA**
}

\begin{abstract}
$\underline{\text { Abstract }}$
A semi-automated finite element analysis program, in conjunction with user written subroutines, has been demonstrated to successfully predict thermo mechanical histories and grain size evolution. "Double cone" compression specimens were found to be highly efficient for generating data for the recrystallization behavior of UDIMET ${ }^{\circledR}{ }^{1}$ alloy 718. Recrystallization behavior was modelled as having two distinct regimes, dynamic and static; both of which were modelled using typical Mehl-Johnson-Avrami forms. This type of modelling capability is expected to improve the efficiency of the ingot-billet conversion process as well as making possible the development of unique products such as dual property billet.
\end{abstract}

\section{$\underline{\text { Introduction }}$}

Historically, higher and higher levels of turbine engine performance have been achieved by increasing their operating temperature. Close control of grain size has been instrumental in allowing these increases in temperature; small grains near the hub are required for crack initiation resistance while large grains are preferred near the rim for creep resistance. Furthermore, ultrasonic inspectability is greatly improved through grain size reduction. Disk-todisk variations in grain size must be kept to a minimum in order to fully exploit the possible material property and inspectability gains achieved through grain size control.

A typical manufacturing sequence for a turbine disk starts with the primary melting and consumable electrode remelting of an ingot followed by conversion of the ingot to a billet. The billet is then closed die forged into a disk blank which is

\footnotetext{
${ }^{1}$ UDIMET is a registered trademark of Special Metals Corporation
}

followed by final machining. Each of these steps is typically, though not always, carried out by a separate manufacturer.

The conversion process of ingot to billet is called cogging and is accomplished by hot working the ingot; usually with open die forging, to induce recrystallization. In the last decade, this billet has become a controlled grain size product unto itself to enable improved inspectability and reduce operations and costs for the forgers of disks. This process will involve many reheats and forging passes. Its development and improvement can be very costly and time consuming. Reduction of the time and cost of this process can be achieved through numeric simulation of the cogging process and microstructural evolution prior to industrial trials and certification.

There are many well established grain size evolution models for nickel base superalloys including:

1. Mehl-Johnson-Avrami type models

2. dislocation based models

3. simple lookup tables

Most share the common elements of predicting grain size based upon prior grain size, temperature, strain, strain rate and hold time. A considerable amount of work has been conducted to integrate these models into finite element codes. This work has been quite successful for cases such as disk blanking where you can use an axisymmetric (2D) finite element analysis and only need to model a few deformation strokes. The case of cogging is quite a bit more complicated as you cannot take advantage of axisymmetry and the process typically involves thousands of deformation strokes and several reheats, each of which requires a separate analysis whose initial conditions are derived from the results of the previous analysis. 
If run manually, the analyst would perform a finite element analysis for a single deformation stroke. When the analysis of this deformation stroke was finished, the analyst would then invoke the preprocessor to read in the end results of the previous deformation stroke to be used as the initial condition for the next analysis. When any given deformation stroke can take between several minutes and several hours to complete, it is obvious that this process takes considerable amounts of time. If run in a manual mode by a single analyst, the computer would be incapable of computing 24 hours per day but would be restricted to those hours that the analyst is available; thereby introducing an artificial "slow-down" of over 50\%. Furthermore, a mistake early in the process can lead to erroneous results at the end of an extremely long modelling effort (the author is aware of several modelling runs aborted after six weeks of effort). The use of a "template" in which the cogging parameters including number of reheats, number of passes per reheat, number of deformation strokes per pass are specified and then used to automate this process has been instrumental in carrying out these evaluations. Considerable effort has gone into making this template robust, easy to use yet sufficiently flexible to handle a wide variety of pass scheduling requirements.

This paper will explore modelling of two cogging processes. The first case is for cogging on a hydraulic radial forge machine in which grain size is directly predicted. The second is a process modification to improve homogeneity of final grain size in billed produced my more traditional open die press forging by changing cogging parameters to improve strain homogeneity throughout the billet. These two examples will show that direct prediction of grain size evolution is possible but that less sophisticated efforts can also yield significant product improvements.

For the case of the radial forge analysis, grain size will be predicted for a single reheat cogging sequence. For the open die forging, the effects of changing certain cogging parameters will be examined. The modifications were designed to "homogenize" the strain and strain rate distributions within the billct in an effort to reduce the variation in grain size.

\section{$\underline{\text { Material }}$}

The material chosen for this study was UDIMET ${ }^{\circledR}$ alloy 718. It's nominal composition is shown in Table I.

Table I: UDIMET Alloy 718 Composition wt\%

\begin{tabular}{|c|c|c|c|c|}
\hline $\mathrm{C}$ & $\mathrm{Cr}$ & $\mathrm{Fe}$ & $\mathrm{Mo}$ & $\mathrm{Nb}+\mathrm{Ta}$ \\
\hline 0.020 & 17.35 & 17.00 & 2.80 & 5.30 \\
\hline \hline $\mathrm{Ti}$ & $\mathrm{Al}$ & $\mathrm{B}$ & \multicolumn{2}{|c|}{$\mathrm{Ni}$} \\
\hline 0.85 & 0.40 & 0.0020 & \multicolumn{2}{|c|}{$\mathrm{Bal}$} \\
\hline
\end{tabular}

\section{Recrystallization Models}

The literature contains a great number of articles concerning recrystallization and cogging of nickel base superalloys. [1-6] These models have generally taken one of three forms as stated previously. Regardless of the model, there are two well accepted regimes of recrystallization along with a slightly controversial third type. In general, during load application, an original unrecrystallized grain may recrystallize dynamically. If $100 \%$ dynamic recrystallization is not achieved the remaining unrecrystallized portions of the original grain may undergo further recrystallization without additional strain input. Some authors call this "meta-dynamic" recrystallization since the principal driving force for recrystallization is the removal of dislocations introduced in the previous deformation. The third regime is static recrystallization and grain growth in which the principal driving force is the reduction of grain boundary energy. The factors affecting each of these types of recrystallization for any given material are :

1. Static

- Hold time

- Residual dislocation density

- Temperature

- Initial grain size

2. Dynamic

- Strain

- Strain rate

- Temperature

3. Meta-Dynamic

- Strain

- Strain rate

- Temperature

- Initial grain size

- Hold time

Regardless of the recrystallization model chosen, dynamically recrystallized and meta-dynamically recrystallized grain size may be reduced by increasing the total strain or strain rate. Increasing the temperature or hold time tends to increase the meta-dynamic or statically recrystallized grain size.

This author has chosen to model the recrystallization phenomenon by breaking it down into dynamic and static components without addressing the "meta-dynamic" possibilities. The modelling is Mehl-Johnson-Avrami based [7,8] with critical strains and strain rates to achieve static and dynamic recrystallization respectively. 
Dynamic Recrystallization

Dynamic recrystallization will only occur if sufficient strain rates and strains are achieved. (i.e. if $\varepsilon>\varepsilon_{\text {crit }}$ and

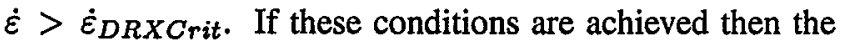
recrystallized fraction and grain size will be given by:

$$
\begin{aligned}
X_{d y n} & =1-\exp \left[-\ln k\left(\frac{\varepsilon}{\varepsilon_{0.5}}\right)^{n}\right] \\
d_{d y n} & =C_{1} Z^{m}
\end{aligned}
$$

Where $\varepsilon$ is the applied strain, $k, n, C_{1}$ and $m$ are material constants, $\varepsilon_{0.5}$ is the strain required to achieve $50 \%$ recrystallization and $Z$ is the traditional Zener-Hollomon parameter given by:

$$
Z=\dot{\varepsilon} \exp \left(\frac{Q}{R T}\right)
$$

$\underline{\text { Static Recrystallization }}$

Static recrystallization will only ocurr if there has been sufficient accumulation of plastic strain. (i.e. $\varepsilon_{p}>$ $\left.\varepsilon_{S R X C r i t}\right)$ If this is achieved, then the fraction recrystallized and recrystallized grain size will be given by:

$$
\begin{aligned}
X_{\text {sta }} & =1-\exp \left[-\ln k\left(\frac{t}{t_{0.5}}\right)^{n}\right] \\
\text { with } t_{0.5} & =t_{0.5}\left(d_{o}, \dot{\varepsilon}, Z\right) \\
d_{s t a} & =C_{2} \varepsilon^{n_{1}} d_{o}{ }^{n_{2}} Z^{n_{3}}
\end{aligned}
$$

Where $t$ is the incremental time, $t_{0.5}$ is the time required to achieve $50 \%$ recrystallization, $\mathrm{k}, \mathrm{C}_{2}, \mathrm{n}$ are material constants and $d_{o}$ is the initial grain size.

\section{Experimental Procedures}

Numeric Simulation of Cogging:

All thermomechanical simulation of the cogging process was done using the commercially available finite element package, DEFORM3 $($ This is a large $3 \mathrm{D}$ deformation code specialized for the forging environment. A "template" was developed by Scientific Forming Technologies Corporation $^{2}$ in order to make more tractable the problem of running many simulations sequentially. Essentially, this template sets up a batch job to run thousands of linked simulations with the output from one simulation serving as the input for the next simulation. In this template, the following parameters are specified:

\footnotetext{
${ }^{2}$ Scientific Forming Technologies Corporation 5038 Reed Road

Columbus, Ohio 43220-2514

(614) $451-8313$
}

www.deform.com
1. Material

2. Heat exchange environment

3. Billet geometry

4. Die geometry

5. Die movement parameters

6. Reheat furnace temperature

7. Number of reheats

8. Number of passes per reheat

9. Billet advance per "bite"(travel increment across dies)

10. Draft per "bite"

11. Billet rotation per pass

After obtaining the complete thermomechanical history (strain, strain rate and temperature as a function of time) of a billet undergoing conversion, the grain size was predicted using Mehl-Johnson-Avrami type models. A user written subroutine was integrated into the DEFORM3 postprocessor. This subroutine is of a modular nature and thus will permit easy incorporation of different recrystallization models as they are developed and effectiveness proven.

Although there is a dependence of yield stress upon grain size, flow behavior was modelled to be only a function of temperature and strain rate and taken from material of intermediate grain size. Although this will cause errors in the prediction of adiabatic heating, the degree of error is relatively small and did not justify increasing either the complexity of the yield constitutive equation or the increase in computational time required. In other words, all predictions of grain size refinement were done on a "postprocessing basis."

\section{Recrystallization Data Generation:}

Generating recrystallization data for the three recrystallization modes requires samples with different initial grain size, temperature, hold time, strain and strain rate. In order to reduce the time and expense of testing, "double cone" compression specimens were chosen due to their ability to generate a wide variety of strains and strain rates within a single specimen. A typical "double cone" geometry and strain variation is shown in Figure 1 . Similar variations are found for the strain rate as shown in Figure 2.

Typical microstructures for different specimen locations for a specimen tested at $1074^{\circ} \mathrm{C}$ with a post test hold time of 60 seconds are in Figures 3 and 4.

\section{Analysis and Results}

As mentioned in the introduction, two different types of cogging were modelled; traditional open die cogging and radial forge machine cogging in order to show that: 


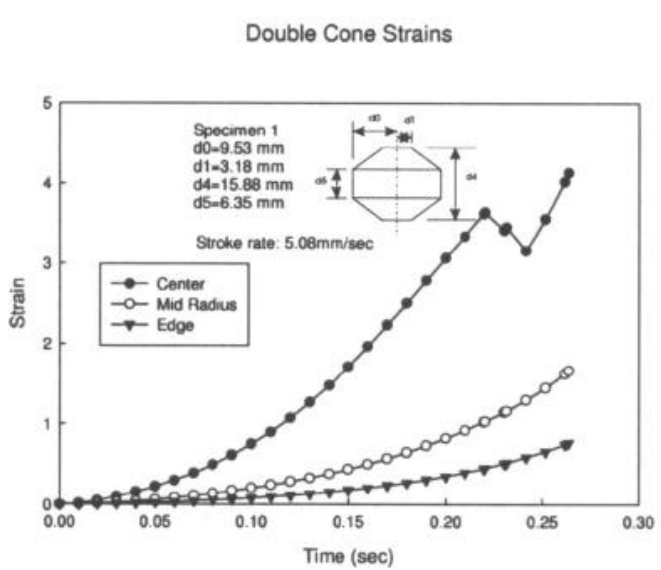

Figure 1: Strain evolution in double cone specimen.

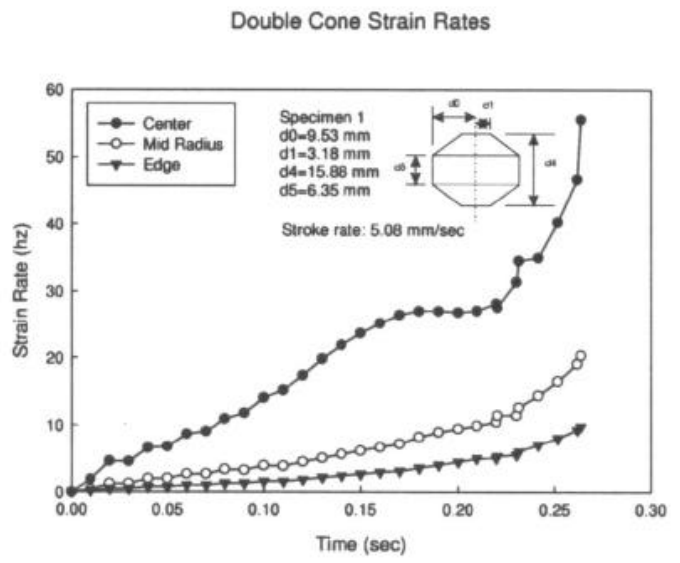

Figure 2: Strain rate evolution in double cone specimen.

1. Analysis of strain and strain rate fields often gives sufficient information to improve a process without the need for grain size refinement modelling.

2. The relatively simple breakdown of recrystallization phenomena into dynamic and static regimes give sufficient information to make good grain size predictions.

For the case of traditional open die forging, modifications were made to a set of existing forging sequences in order to decrease the variation in grain size as a function of position within the billet and to reduce the grain size. Changes were made to the cogging parameters for all reheats of the conversion process including the total reduction per reheats. The two cases modelled were cogging of a $430 \mathrm{~mm}$ round corner square (RCS) billet to a $380 \mathrm{~mm}$ octagon billet and a $460 \mathrm{~mm}$ RCS billet to a $406 \mathrm{~mm}$ octagon billet. These are practices 1 and 2 respectively. The total reduction in cross

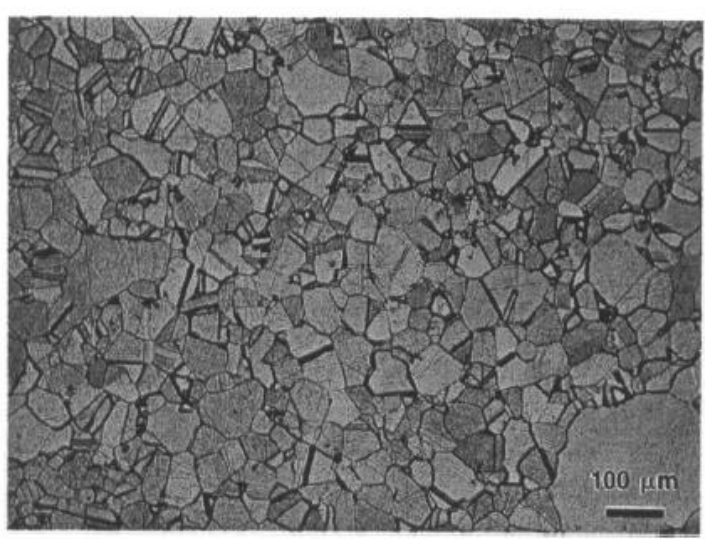

Figure 3: Recrystallization near specimen edge with low deformation.

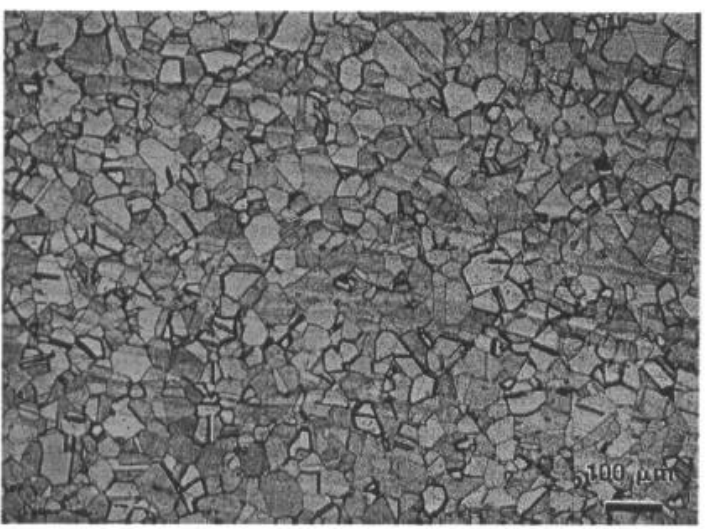

Figure 4: Recrystallization near specimen center with high deformation.

sectional areas are only very slightly different; $\approx 28 \%$ for practice 1 and $\approx 27 \%$ for practice 2 . Most pertinent details of the cogging sequences are shown in Tables II and III.

Table II: Original reheat sequence

\begin{tabular}{|c|c|c|c|}
\hline Pass & $\begin{array}{c}\text { Forge to Size } \\
\text { (mm) }\end{array}$ & $\begin{array}{c}\text { Bite Advance } \\
\text { (mm) }\end{array}$ & $\begin{array}{c}\text { Rotation } \\
\text { (deg) }\end{array}$ \\
\hline \hline 1 & 381.0 & 190.5 & 90 \\
2 & 381.0 & 190.5 & 90 \\
3 & 381.0 & 190.5 & 90 \\
4 & 381.0 & 190.5 & 90 \\
5 & 419.1 & 190.5 & 45 \\
6 & 419.1 & 190.5 & 90 \\
7 & 381.0 & 190.5 & 90 \\
8 & 381.0 & 190.5 & 90 \\
9 & 381.0 & 190.5 & 45 \\
10 & 381.0 & 190.5 & 90 \\
11 & 381.0 & 190.5 & -45 \\
12 & 381.0 & 190.5 & 90 \\
\hline
\end{tabular}


Table III: Modified reheat sequence

\begin{tabular}{|c|c|c|c|}
\hline Pass & $\begin{array}{c}\text { Forge to size } \\
\text { (mm) }\end{array}$ & $\begin{array}{c}\text { Bite Advance } \\
\text { (mm) }\end{array}$ & $\begin{array}{c}\text { Rotation } \\
\text { (deg) }\end{array}$ \\
\hline \hline 1 & 444.5 & 147.3 & 45 \\
2 & 444.5 & 147.3 & 90 \\
3 & 406.4 & 134.6 & 45 \\
4 & 406.4 & 134.6 & 90 \\
5 & 406.4 & 203.2 & 90 \\
6 & 406.4 & 203.2 & 45 \\
7 & 406.4 & 203.2 & 90 \\
8 & 406.4 & 203.2 & 90 \\
9 & 406.4 & 228.6 & 45 \\
10 & 406.4 & 228.6 & 90 \\
11 & 406.4 & 254.0 & -45 \\
12 & 406.4 & 254.0 & 90 \\
\hline
\end{tabular}

For the case of the radial forge machine cogging, pertinent details of the cogging sequences are shown in Table IV.

Table IV: SMX-420 sequence

\begin{tabular}{|c|c|c|c|c|}
\hline Pass & Shape & $\begin{array}{c}\text { Forge } \\
\text { to size } \\
(\mathrm{mm})\end{array}$ & $\begin{array}{c}\text { Bite } \\
\text { Advance } \\
(\mathrm{mm})\end{array}$ & $\begin{array}{c}\text { Rotation } \\
\text { per Bite }\end{array}$ \\
\hline \hline 0 & Octagon & 355.0 & 0.0 & 0.0 \\
1 & Round & 328.2 & 60.0 & 30.0 \\
2 & Round & 295.5 & 60.0 & 30.0 \\
3 & Round & 266.0 & 60.0 & 30.0 \\
4 & Round & 266.0 & 25.0 & 15.0 \\
\hline
\end{tabular}

Thermomechanical histories of open die cogging sequences

The evolution of strain, strain rate and temperature for various points in the billet for Practice 1 and 2 was predicted by finite element analysis. The final state of strain is shown graphically in Figures 5 and 6. (Color versions of figures 5 \& 6 appear on page 839 .)

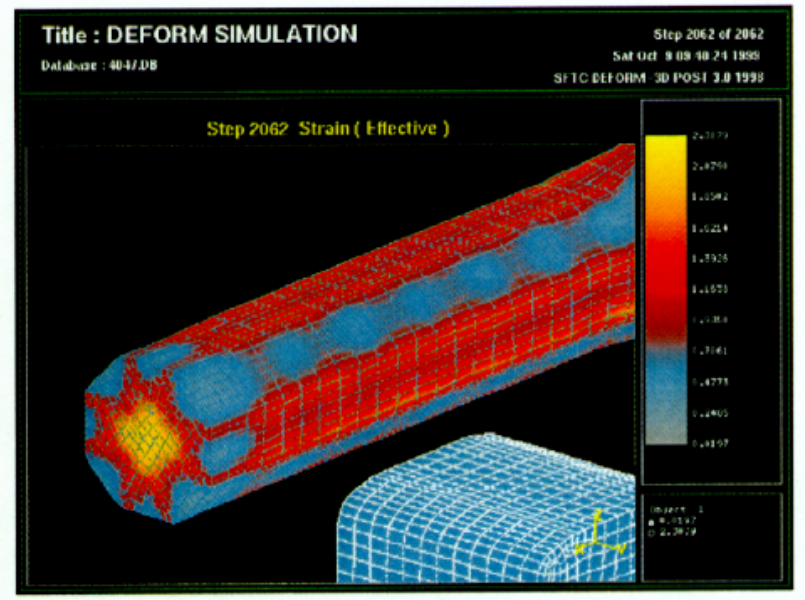

Figure 5: Practice 1: Final state of strain.

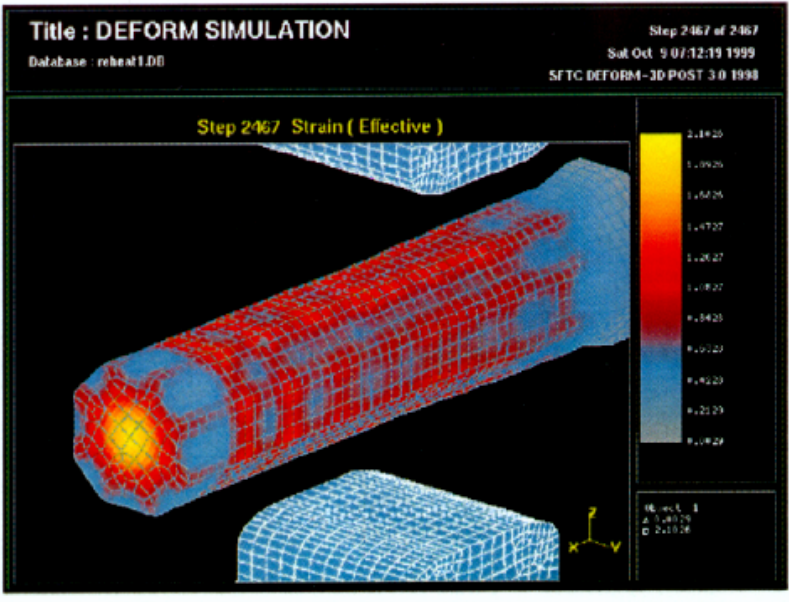

Figure 6: Practice 2: Final state of strain.

Three different line sections of the billet were examined for homogeneity of final cumulative strain. These sections are:

1. Along the centerline in a longitudinal direction in the middle (lengthwise) of the billet, away from end effects

2. $12.7 \mathrm{~mm}$ beneath the surface along a longitudinal direction line in the middle of the billet

3. In a radial direction from the billet centerline to the surface

The results are shown in Figures 7, 8, 9, 10, 11 and 12. It is quite clear that changing the pass schedules has substantially changed the thermomechanical history experienced throughout the billet. Practice 1 produced billets with significant variations in the edge grain size as one moved longitudinally along the billet whereas Practice 2 produced much more uniform edge grain sizes. This is clearly a result of changing the near edge strain distribution. The first sequence produced cumulative strains that varied between 0.55 and 0.80 whereas the modified sequence varied between 0.70 and 0.84 . This is particularly noteworthy in light of the fact that Practice 1 had a greater overall reduction in cross sectional area of the billet. Not only was the variation reduced, the average cumulative strain experienced near the outer surface was increased which resulted in finer grain sizes. The variation in strain experienced along the centerline was increased somewhat for Practice 2 but was still quite low on an overall basis. Finally, Practice 2 clearly biased the deformation towards the surface of the billet whereas Practice 1 biased the deformation towards the center of the billet. This is clearly shown in Figures 11 and 12. 


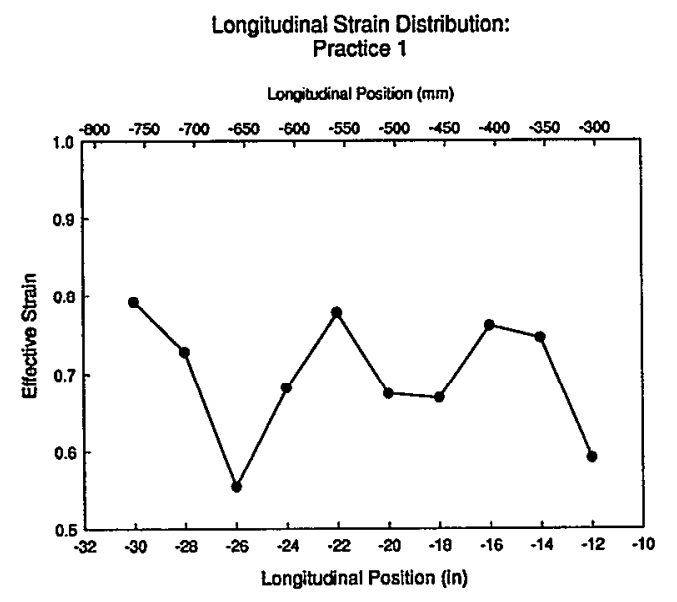

Figure 7: Practice 1: Longitudinal strain variations measured $25 \mathrm{~mm}$ from the surface.

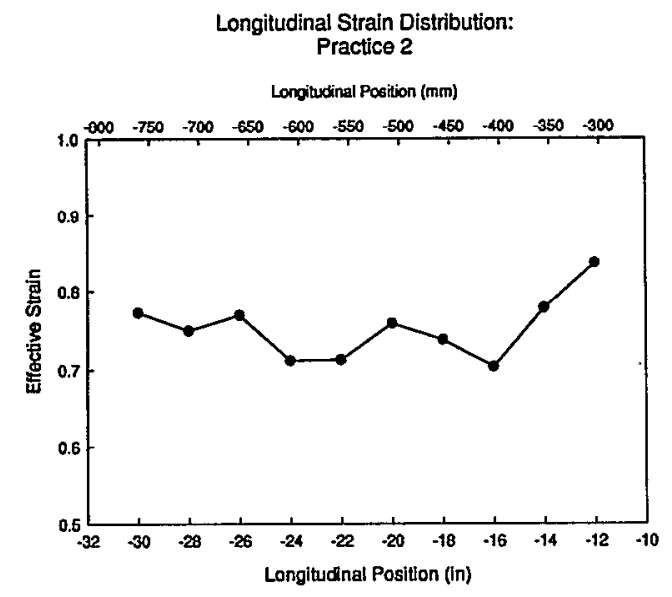

Figure 8: Practice 2: Longitudinal strain variations measured $25 \mathrm{~mm}$ from the surface.

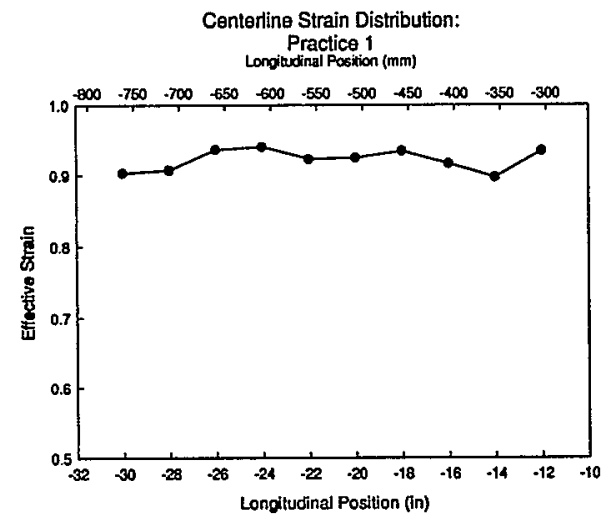

Figure 9: Practice 1: Centerline strain variations.

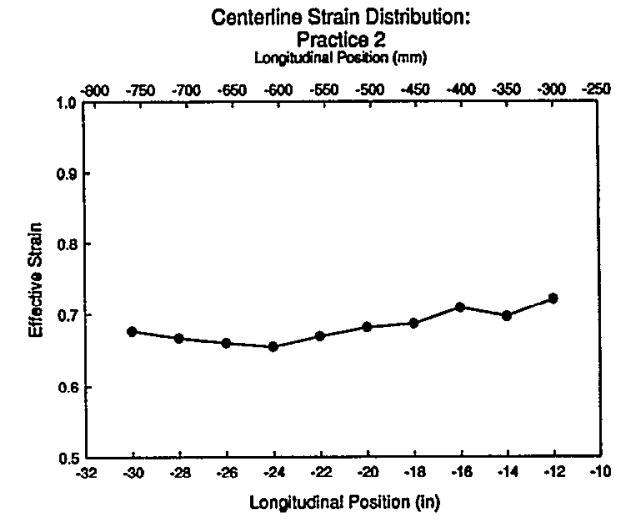

Figurc 10: Practice 2: Centerline strain variations.

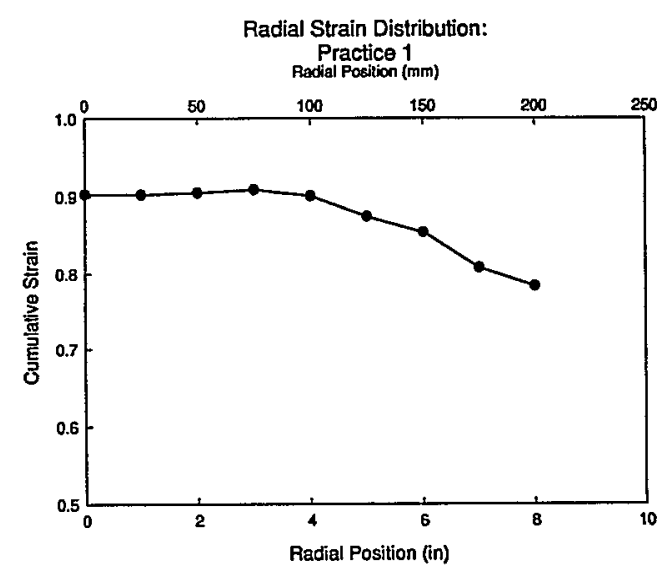

Figure 11: Practice 1: Radial strain variations.

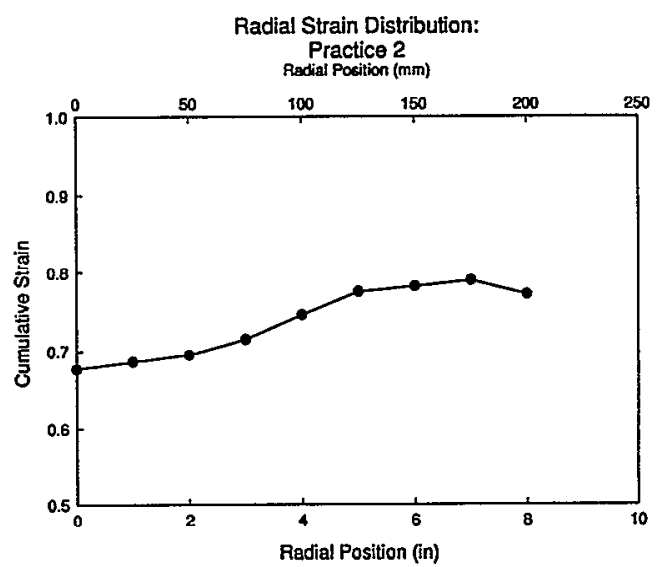

Figure 12: Practice 2: Radial strain variations.

The results of changing the cogging sequence upon final grain size are shown in Figure 13. The modified cogging sequence has clearly reduced the size of both the primary and as large as edge grain size while not significantly 
affecting the center grain size.

10" Fine Grain Udimet ${ }^{\star}$ alloy 718 Billet Grain Size Comparison

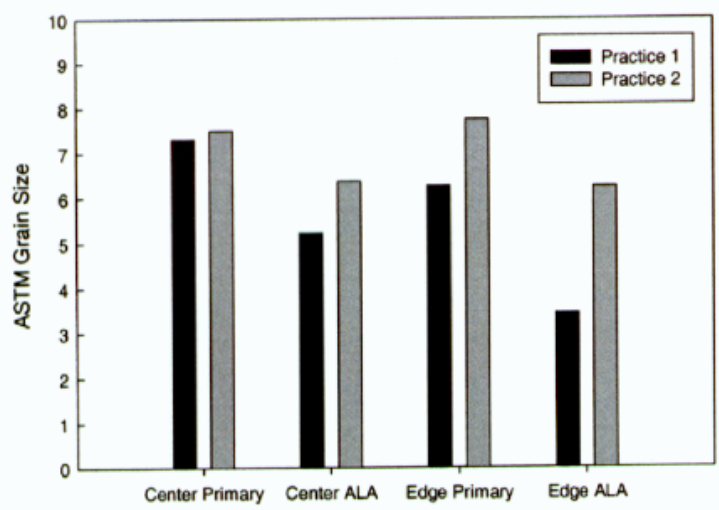

Figure 13: Grain size comparison for the two cogging sequences.

For the case of the cogging with a radial forge machine, predictions of statically recrystallized grain size, dynamically recrystallized grain size and percent fraction dynamic recrystallization are shown in Figures 14, 15 and 16 respectively. It must be noted that these are plots of billet prior to final grinding and polishing in which approximately $10-20 \mathrm{~mm}$ of material in the radial direction is removed. Therefore, when comparing the predicted and measured grain sizes at the billet edge as shown in Table V, one must be careful to examine the predicted grain size on the finite element plots at approximately $10-20 \mathrm{~mm}$ beneath the surface. (Figures 14-16 appear in color on pages 839-840.)

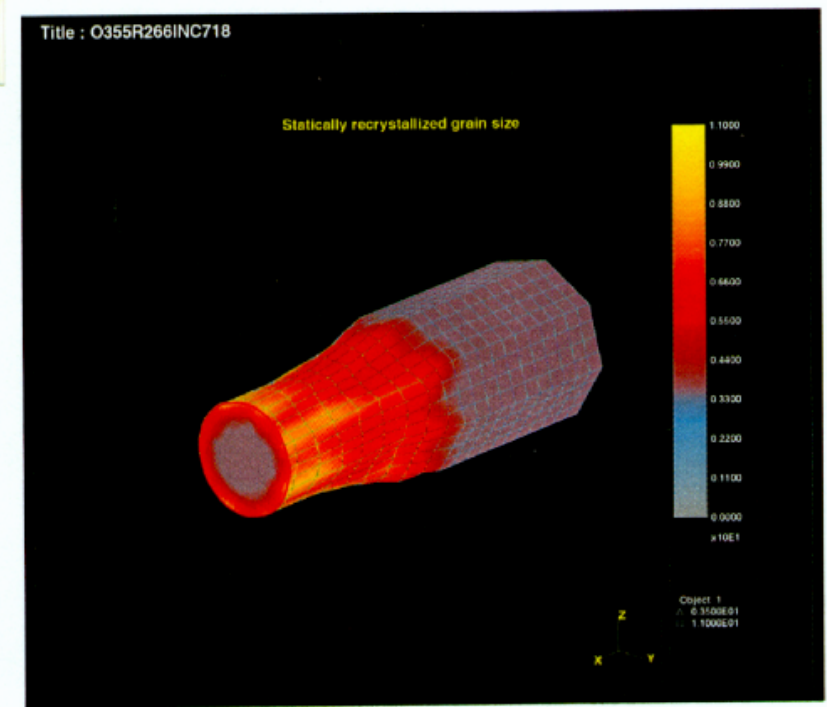

Figure 14: Statically recrystallized grain size. Predicted grain size ranges from ASTM 5.5 at center to 6.0 near edge.

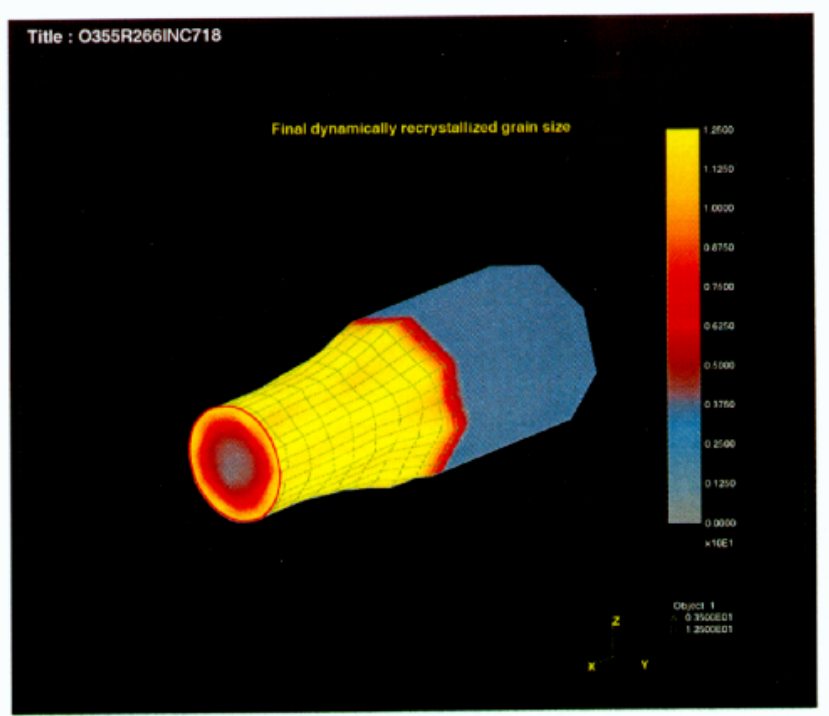

Figure 15: Dynamically recrystallized grain size. Predicted grain size ranges from ASTM 3.5 at center to 7.0 near edge where grain size measurements are made.

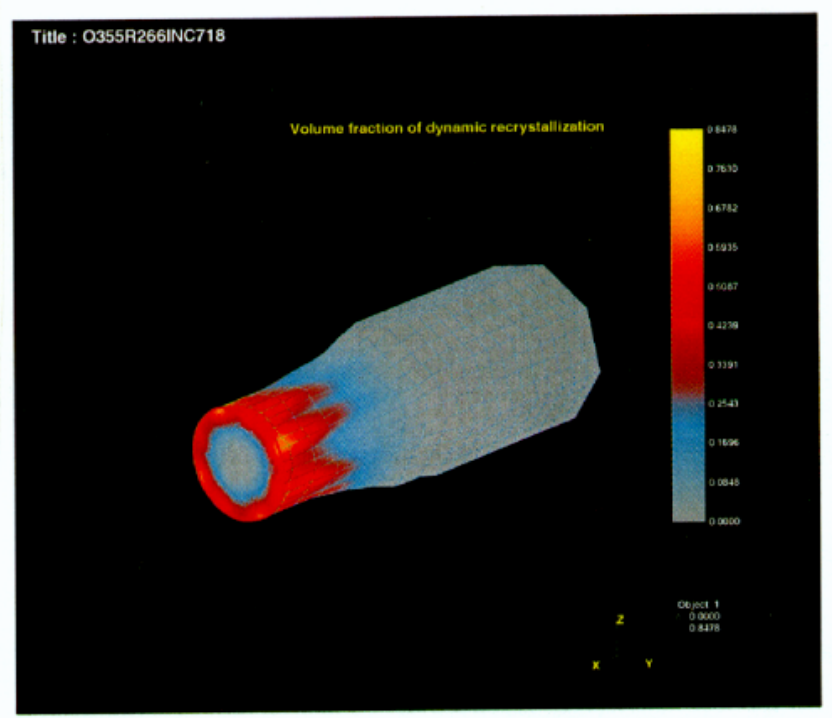

Figure 16: Dynamically recrystallized grain size fraction $\mathrm{Rx}$

\section{Grain size predictions for Rotary forge "cogging"}

Using the previously discussed models, dynamically recrystallized grain size, statically recrystallized grain size and fraction dynamic recrystallization were predicted. Comparison between measured values and predicted values is shown in Table V. 
Table V: Comparison of predicted and measured grain sizes

\begin{tabular}{|c|c|c|c|}
\hline & $\begin{array}{c}\text { Center } \\
(\mathrm{ASTM})\end{array}$ & $\begin{array}{c}\text { Mid-Radius } \\
(\mathrm{ASTM})\end{array}$ & $\begin{array}{c}\text { Near Edge } \\
(\mathrm{ASTM})\end{array}$ \\
\hline $\begin{array}{c}\text { Prediction } \\
\text { (SRX) }\end{array}$ & 5.5 & 5.5 & 6.0 \\
\hline $\begin{array}{c}\text { Prediction } \\
\text { (DRX) }\end{array}$ & 3.5 & 5.0 & $\begin{array}{c}7.0 \\
V_{f} \approx 30 \%\end{array}$ \\
\hline Measured & 6.0 & 7.0 & $\begin{array}{c}3 \\
15 \% 5.5\end{array}$ \\
\hline
\end{tabular}

Examination of the finite element plots and tabulated date for static recrystallization, dynamic recrystallization and volume fraction of dynamic recrystallization shows that:

1. Near the center, there is insufficient strain to achieve significant volume fractions of dynamic recrystallization

2. Near the center, there is sufficient strain to achieve static recrystallization

3. Near the surface $\approx \approx 10-15 \mathrm{~mm}$ subsurface, there is sufficient strain to achieve approximately $30-40 \%$ dynamically recrystallized grains of ASTM 7.

\section{Applications}

As is well known, there is a great desire on the part of engine manufacturers to produce so called "dual property" disks with small grains on the hub for LCF resistance and large grains on the circumference for good creep resistance. Efforts in the past to accomplish this have taken the form of selective induction heating on the disk circumference as well as welding different materials together to form a single disk. Both of these have obvious drawbacks including:

1. Extra processing on the part of the billet supplier to produce uniform fine grain which is subsequently removed

2. Difficulty in achieving uniformly large grain size in the geometrically complex blade attachment points

3. Crack initiation at the heat affected zone

Given the fact that the disk forger has areas in the disk which receive little deformation and little potential for grain size refinement, one elegant solution is to supply billet with an appropriate heterogeneous grain size. Through careful attention to reheat temperatures, bite advance, bite draft and die speed, it is theoretically possible to produce such a billet. The amount of industrial trials required in the past to perfect this process were prohibitive. In theory and practice, these billets may now be produced.

\section{Conclusions}

It has been shown conclusively that the use of finite element modelling can adequately predict billet thermo-mechanical histories and associated microstructural evolution during the cogging process. The development and use of a cogging "template" has been instrumental in allowing the analysis of "real world" cogging problems by allowing extremely complicated simulations with many "bites" per pass, multiple passes per reheat and multiple reheats. When used in conjunction with post processing based recrystallization models, sufficiently accurate grain size evolution predictions can be made to reduce the amount of required full scale testing to validate new cogging sequences. This process is now sufficiently robust, with sufficient ease of use, to be used on a regular basis as a critical tool in pass scheduling development. The trials conducted have also numerically confirmed and quntified the benefits of precise control of cogging parameters such as "draft", "bite", rotational orientation of workpiece, etc., for the manufacture of billet for today's turbine engine disks.

\section{$\underline{\text { References }}$}

[1] G. Shen, S.L. Semiatin, and R. Shivpuri. Modeling microstructural development during the forging of Waspaloy. Metallurgical Transactions A, 26A,p17951803, 1995.

[2] C.A. Dandre, S.M. Roberts, R.W. Evans, and R.C. Reed. Microstructural evolution of Inconel 718 during ingot breakdown process modelling and validation. Materials Science and Technology, 16,1,p14-25, 2000.

[3] F.J. Humphreys and M. Hatherly. Recrystallization and Related Annealing Phenomena. Oxford; New York; Yushimi: Pegramon Press, 1995, 1 edition, 1995.

[4] D. Zhao, S. Guillard, and A.T. Male. High Temperature Deformation Behavior of Cast Alloy 718 . In Superalloys 718, 625, 706 and Various Derivatives, pages 193-204, 1997.

[5] Laurance A. Jackman, M.S. Ramesh, and Robin Forbes Jones. Development of a Finite Element Model For Radial Forging of Superalloys. In Superalloys 1992, pages 103-112, 1992.

[6] A.K. Chakrabarti, M.R. Emptage, and K.P. Kinnear. Grain Refinement in IN-706 Disc Forgings Using Statistical Experimental Design and Analysis. In Superalloys 1992, pages 517-526, 1992.

[7] Melvin Avrami. Kinetics of Phase Change. General Theory. Journal of Chemical Physics, 7,p1103-1112, 1939. 
[8] Melvin Avrami. Kinetics of Phase Change. Transformation-Time Relations for Random Distribution of Nuclei. Journal of Chemical Physics, 8,p212-224, 1940. 